\title{
Wholesale electricity market design with increasing levels of renewable generation, Part II: Incentivizing flexibility in system operations
}

It is unclear whether current market designs are incentivizing resources to offer their flexible capabilities to the short-term energy and/or ancillary services market when active power flexibility is needed the most. Flexibility may benefit from new ancillary service market designs, such as pay-for-performance regulation and primary frequency response markets, as well as explicit products for flexible ramping provision of the type proposed in CAISO and MISO.

E. Ela, ${ }^{1}$ M. Milligan, ${ }^{2}$ A. Bloom, ${ }^{2}$ A. Botterud, ${ }^{3}$ A. Townsend, ${ }^{2}$ T. Levin, ${ }^{3}$ and B. Frew $^{2}$

${ }^{1}$ Electric Power Research Institute

${ }^{2}$ National Renewable Energy Laboratory

${ }^{3}$ Argonne National Laboratory

Erik Ela is Senior Technical Leader at the Electrical Power Research Institute. He is an expert in bulk power system operations, technical wholesale market design implementations, large-scale power system planning and the evolution of these topics with a changing resource mix. Dr. Ela has a B.S., M.S., and Ph.D. in Electrical Engineering.

Michael Milligan is a Principal Analyst in the Power Systems Engineering Center at the National Renewable Energy Laboratory. He has published more than 200 technical reports, journal articles, and book chapters on wind and solar integration and participates on the leadership team for numerous electricity advisory and working groups. Dr. Milligan holds a Ph.D. in Economics from the University of Colorado, Boulder.

Aaron Bloom manages a team of power system modelers in the Strategic Energy Analysis Center at the National Renewable Energy Laboratory. He is an expert in electricity market design and ratemaking. His work at NREL focuses on capacity expansion, system planning, and grid operations. Mr. Bloom holds a Master of Public Administration from The Ohio State University's John Glenn College of Public Affairs. 
Audun Botterud is a Principal Energy Systems Engineer in the Center for Energy, Environmental and Economic Systems Analysis at Argonne National Laboratory. His research interests include power systems planning and economics, electricity markets, grid integration of renewable energy, energy storage, and stochastic optimization. Dr. Botterud holds a M.Sc. in industrial engineering and Ph.D. in electrical power engineering, both from the Norwegian University of Science and Technology.

Aaron Townsend is an energy systems analyst at the National Renewable Energy Laboratory. He researches electricity market design and integration of renewable technologies in the electric power sector. He holds a Ph.D. from the University of Texas at Austin.

Todd Levin is an Energy Systems Engineer in the Center for Energy, Environmental and Economic Systems Analysis at Argonne National Laboratory. His research interests focus on utilizing advanced optimization and simulation methodologies to model complex interactions in electricity markets and quantify the implications of domestic energy policies and regulations. He holds a Ph.D. in industrial engineering from the Georgia Institute of Technology.

Bethany Frew is a Postdoctoral Researcher in the Strategic Energy Analysis Center at the National Renewable Energy Laboratory. Her primary research interest is to better understand how to meet electricity system needs with high penetrations of renewable energy through technical and institutional mechanisms. She holds a Ph.D. in Civil and Environmental Engineering from Stanford University.

Keywords: Electricity markets, variable generation, variability, uncertainty, flexibility, ancillary services

\section{Introduction}

The characteristics of variable generation (VG) such as wind and photovoltaic solar create unique challenges in planning and operating the power system. VG increases the variability and uncertainty of net load (load minus VG), has near-zero or zero variable production costs that can become negative in the presence of production-based subsidies, and has diurnal and seasonal patterns that are often non-coincident with critical peak load periods. With the substantial increase in VG in recent years, the resources in the system will have to be more flexible to adjust output so that power output ranges, power ramp rates, and energy duration sustainability are sufficient to meet the needs of balancing supply with demand at various operational timescales and to allow for maximum utilization of VG. Just as important, market designs will have to make sure the flexible resources are incentivized to provide their flexibility when needed.

This article is the second in a series of two that focus on specific market design issues that arise from the VG characteristics listed above: the first focused on resource adequacy and revenue 
sufficiency for long-term reliability, and this article on incentivizing flexibility in short-term operations. We discuss the extent of how existing market designs provide adequate incentives for resources to offer and provide their flexibility into the market during the operational time frame. We explore how markets in the United States currently incentivize resources to offer flexibility, discuss how these designs are evolving due in large part to the growing presence of VG in the system, and discuss how this need will affect electricity market designs in the future. Issues related to the investment time horizon and the installation of resources (new or upgrades) with sufficient flexibility capabilities are addressed in the first article in this series (Milligan et al. 2016).

\section{Defining flexibility}

Flexibility as a term is gaining popularity in the electric power industry. For clarity, we provide a definition of power system flexibility in system operations as "the ability of a resource, whether any component or collection of components of the power system, to respond to known and unknown changes in power system conditions at various operational timescales." Similar definitions have been proposed by other authors, and a more detailed discussion is provided in Ela et al. (2014c). Different types of resources excel at different forms of flexibility, and they also incur different costs when providing flexibility.

The main characteristics of active power flexibility discussed here will generally fall into three categories: (1) absolute power output capacity range (MW), (2) speed of power output change (MW/min), and (3) duration of energy levels (hours of MW). First, resources that have a large range of absolute output between their minimum and maximum capacity levels can be classified as more flexible because they have greater ability to adjust to changing power system conditions. Resources that can be easily turned on or off provide increased flexibility because the absolute power range can be taken between zero and maximum capacity. For example, constraints that limit thermal plants on how and when they can be committed on and off (e.g., minimum on times, minimum off times, and maximum starts per day limits) affect their ability to provide flexibility. Second, resources that have greater ramp rates or startup times can also be classified as more flexible because they are able to adjust faster to changes in power system conditions of varying speeds. Last, resources that are able to hold energy levels for longer periods of time can 
be classified as more flexible because they are able to better meet power system conditions that sustain significant periods.

Additional characteristics demonstrate a resource's flexibility as well. For example, resources that have automatic control capability, are frequency-responsive, and can contribute to system restoration can be classified as more flexible. Reactive power range and the ability to ride through low-voltage and -frequency conditions are also important flexibility parameters. These qualities are important to ensuring overall power system reliability. In general, the more flexible qualities a resource has, the more valuable it is to the power system.

A lack of active power flexibility can lead to an imbalance in generation and load (which can lead to system frequency excursions), overloading of transmission elements, and other potential reliability issues. Improper utilization of existing flexibility, or unwillingness of resources to provide existing flexibility, can also lead to these reliability issues, or to higher costs if more expensive flexibility is required when economic flexibility is not offered at its full potential. It is important that the increased fuel costs, wear and tear, or other factors associated with providing this flexibility are properly compensated by market structures.

\section{The impact of increasing penetrations of VG on the need for flexibility}

System flexibility is required to meet the known and unknown changes in power system conditions, referred to as variability and uncertainty, respectively. In power systems, the load is variable, both diurnally and at shorter timescales ranging from hours to minutes or less. The load is also uncertain, because it cannot be perfectly predicted at all times and over all time horizons. Conventional generation and transmission elements also have uncertainty, because they can fail unexpectedly. Over time, the industry identified various procedures to accommodate this variability and uncertainty, including operating reserve and security-constrained scheduling models (e.g., n-1 preventative procedures for transmission outages).

VG adds to existing variability and uncertainty of supply and hence net demand on multiple timescales (Ela and O’Malley 2012). The maximum available power changes based on weather conditions, such as wind speed and solar irradiance. This variability in supply causes the 
aggregate net load to change more often and potentially much faster than systems where supply is dispatchable. In turn, the resources used to balance the system need to change output more often and at potentially faster rates. In addition, VG output cannot be predicted perfectly in advance. This uncertainty may require at least some of the balancing to come from fastresponding resources when the output of VG is finally apparent.

The variability and uncertainty of VG can be met by different operational strategies depending on the timescale and time horizon. For instance, short-term (e.g., minute-to-minute) variability might be met by regulating reserve (or regulation), medium-term (e.g., tens of minutes to hours) variability might be met by flexibility reserve, and long-horizon uncertainty might be met by improved forecasting. It is possible that some of the existing procedures for accommodating the variability and uncertainty can be used to meet the increasing impacts of VG. However, it may be that new procedures and tools can do so in a more reliable and efficient manner. Some examples of these evolving strategies include shorter scheduling intervals (Milligan, Kirby and Beuning 2010) to meet increased variability and stochastic or robust unit commitment and dispatch solutions for addressing uncertainty (Bouffard and Galiana 2008, Meibom et al. 2011, Bertsimas et al. 2013). Additionally, incorporating increased look-ahead horizons in the scheduling model and intelligent operating reserve requirements can help meet increased variability and uncertainty if done efficiently (Price and Rothleder 2011, Zhou and Botterud 2014).

In addition, VG is location constrained and nonsynchronous to the electrical frequency. These characteristics can also cause challenges and potentially increase the need for these types of flexibility services from other resources that may be displaced by VG. For example, primary frequency response and synchronous inertia currently are not part of the ancillary services market in the United States, but they may be necessary in the future as penetrations of nonsynchronous VG increase (Ela et al. 2012). It is also possible that VG can create the controls to provide these services itself (Ela et al. 2014a), but that may also depend on the incentives present and whether any revenues from providing this service will justify VG installing these capabilities. If VG is located far from load centers, then localized flexibility such as storage may be required to accommodate the variability and uncertainty of VG without overloading the 
elements of the transmission network. All of these characteristics are causing a greater need for various forms of flexibility from the resources on the power system.

\section{Traditional market design elements that impact flexibility incentives}

The first step in obtaining flexibility from market participants is to have a mechanism that allows the market operator to both commit the resource and dispatch the resource's output when it is needed. Suppliers should be incentivized to allow the market operator to dispatch its output to meet the changing energy and ancillary service demand while still operating within design parameters. An additional property of well-designed markets is being technologically neutralspecifying what is needed in the system and allowing different technologies to compete. We focus on five specific examples of traditional market mechanisms in place to induce resources to offer flexibility to the market operator, therefore allowing the market operator to adjust resource output to meet the changing needs of the system. These include centralized scheduling and efficient dispatch, frequent scheduling and frequent settlement intervals, existing ancillary service markets, make-whole payment guarantees, and day-ahead profit guarantees.

\subsection{Centralized scheduling and efficient dispatch by the market operator}

Current markets have mechanisms that incentivize resources to offer their operating capabilities to be centrally dispatched by the independent system operator (ISO). When suppliers participate in these pool markets, the market operator will operate them at their most efficient operating point based on their offered cost curve. The market operator minimizes the bid-based production costs from all of these resources to meet the energy and ancillary service demands subject to power system security and individual resource constraints. When the price increases, the market operator signals economic suppliers to increase their output, and this allows the suppliers to earn more revenue. Conversely, when the price decreases, the market operator signals suppliers that are no longer economic to reduce output, allowing them to operate in a way that does not cost more than they may earn.

However, a portion of the generating fleet-sometimes as much as $50 \%$ to $70 \%$ of the energy (CAISO 2010b, Monitoring Analytics, LLC, 2010)—operates through bilateral contracts outside 
of the pool-based electricity markets. These suppliers, along with others that are not responding to price signals, are self-scheduled resources that provide the market operator with the scheduled output before the market clears, and this schedule is fixed regardless of the price. Although the market operators still receive the energy from the resources to meet the expected demand, they do not have any flexibility from these self-scheduled units to meet ancillary service demands or changing energy demands. When substantial bilateral contracts are self-scheduled into the market, the system operator may not have sufficient flexibility available. It is important to note that the levels of physical flexibility may be sufficient; however, some of this may not be contractually available.

To illustrate the potential impacts of self-scheduling, we show a simple example using real bidcost data for a thermal generating unit (Table 1). This bid-in cost curve forms the basis of how this resource would bid into the market and reflects representative costs of thermal plants based on a convex, monotonically increasing incremental heat rate. We ignore no-load costs in this example for simplicity. The incremental cost in column 1 is the cost bid for the specific capacity represented in column 2 . Therefore, the first $286 \mathrm{MW}$ in this example will always cost (35*286) $=\$ 10,010$.

Figure 1 shows the relationship between these cost data and a 12-hour period of locational marginal pricing (LMPs) (solid black line) and how various self-scheduling strategies (thin dashed lines) compare to how the unit would be dispatched by the market operator in the absence of self-scheduling (thickest gray dashed line), under the assumption that the unit is a price taker. For simplicity, ramp rates and other operational constraints are ignored. ${ }^{1}$ The different scheduling strategies include: "Market Operator" with efficient dispatch of the resource every hour, "Mid Self Sched" with supplier self-scheduling itself at a level between its minimum and maximum capacity for all hours, "Min Self Sched" with supplier self-scheduling itself at its minimum capacity level, "Max Self Sched" with supplier self-scheduling itself at its maximum capacity level, and "Lag LMP" with supplier using the LMP from the previous hour to predict where it should self-schedule itself for the following hour. 
Table 1. Hypothetical Thermal Plant, Piecewise Linear Cost Curve

\begin{tabular}{|l|l}
\hline $\begin{array}{c}\text { Incremental Cost } \\
(\text { \$/MWh) }\end{array}$ & $\begin{array}{c}\text { Energy/ } \\
\text { Capacity Segment } \text { (MWh) }\end{array}$ \\
\hline 35.00 & Up to 286.0 \\
47.25 & $286.1-295.0$ \\
47.60 & $295.1-304.0$ \\
47.95 & $304.1-313.0$ \\
\hline 48.30 & $313.1-322.0$ \\
\hline 48.65 & $322.1-331.0$ \\
\hline 49.00 & $331.1-340.0$ \\
\hline 49.35 & $340.1-349.0$ \\
\hline 49.70 & $349.1-358.0$ \\
\hline 50.75 & $358.1-376.0$ \\
\hline 52.50 & $376.1-377.0$ \\
\hline
\end{tabular}




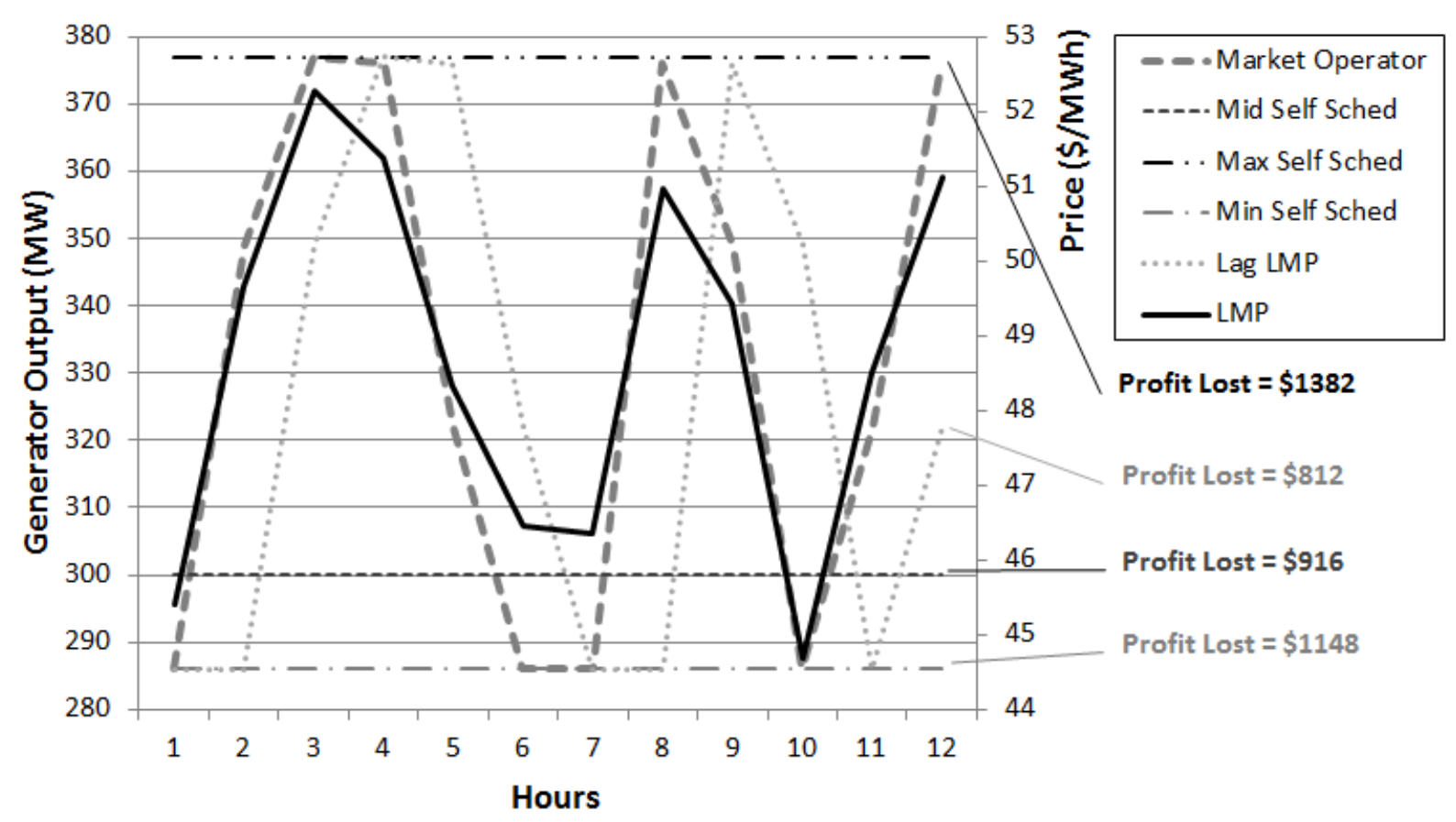

Figure 1. Profit lost for various self-scheduling techniques (adapted from Ela et al. 2014c)

Also shown on the right side of Figure 1 is the impact of self scheduling versus offering full flexibility on profit. Under good electricity market design, the supplier output level should always reflect the changing prices and should avoid operating at levels that cost more to produce energy than the price they receive. Centralized scheduling leads to more efficient prices that should, in theory, provide greater profit to resources that offer flexibility compared to those that self-schedule their output. As shown in Figure 1 for each case relative to the efficient Market Operator scenario, profit is maximized when the market operator schedules the resource, and profit is reduced when it self-schedules itself in any manner. This is true even with intelligence in the "Lag LMP" self-scheduling strategy. Although the lost profit is small relative to the total profit in each case, it will be highly dependent on the cost curve and prices during different time periods.

\subsection{Five-minute scheduling and 5-minute settlements}

As discussed, resources can be operated differently based on preset schedules or by a centralized operator. All market regions in the United States now schedule the real-time output of resources at 5-minute intervals. Frequent scheduling and shorter settlement intervals allow for better pricing of actual conditions and provide incentives for resources that can follow the prices. Five- 
minute settlements, which are related to but not identical to 5-minute scheduling, occurs if the resources are paid based on the 5-minute schedules and 5-minute prices rather than based on hourly averages of the 5-minute schedules and prices. This settlement is done only in a few of the markets today, including New York Independent System Operator (NYISO) and Southwest Power Pool.

Because ramp constraints are used in the market-clearing model to constrain the ability of a supplier to sell energy into the market when they do not have the flexibility to follow prices, the selection of supply into the energy market should be based on the actual capability of resource ramp rates for the scheduling and dispatch time resolution. Most of the 5-minute energy markets that are currently in place in the United States do a good job of extracting flexibility without resorting to a separate market for a specific product for ramping capability. Because unit set points are calculated so frequently, many units ramp a substantial portion of the time. This allows for the most economic provision of energy given the constraints on the transmission system, and units can take advantage of price volatility when they can ramp faster.

However, in some instances, the ramp constraints can give the opposite effect. A faster, more expensive unit will be used to make up for a ramp-constrained resource, thus setting the price while at the same time giving a higher revenue opportunity for the slower unit. Milligan and Kirby (2010) provide a simple illustration with no look-ahead ability and only two generators: a baseload unit that has a marginal cost of $\$ 10 / \mathrm{MWh}$ and a peaking unit that has a marginal cost of \$90/MWh, as illustrated in Figure 2. During a steep ramp that is beyond the speed at which the baseload unit can respond, but within its capacity range, the peaking unit is dispatched to cover the ramp and meet the load. After the baseload unit catches up, the peaking unit is shut off. The peaking unit sets the energy price at $\$ 90 / \mathrm{MWh}$ during the time it is used to meet the load during the ramp period. Although this is not a problem per se, the baseload unit also collects $\$ 90 / \mathrm{MWh}$ during this period, which may not provide the baseload unit any incentive to become more flexible, and in fact it may provide a disincentive. This topic should be studied further to see what consequences may occur. One solution is a multi-period dispatch that looks ahead to ensure that units can meet upcoming ramping requirements such that the price may dip at the beginning of the ramp and cause the baseload unit to make similar revenue. Many U.S. market operators 
have or are developing proposals to move toward multi-period dispatch when solving the realtime market (FERC 2014).

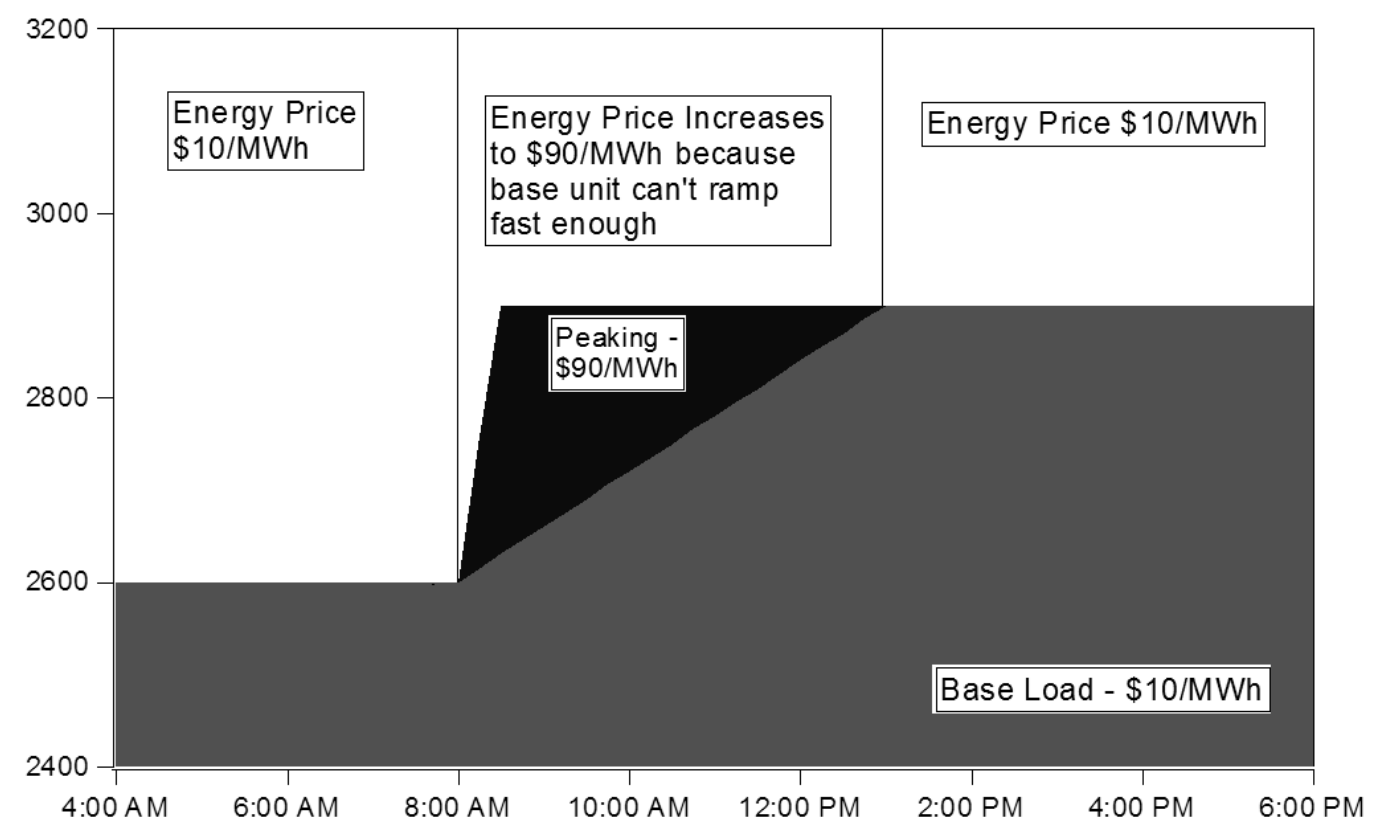

Figure 2. Simple example of ramp-limited resources and resulting prices (adapted from Milligan and Kirby 2010)

To illustrate how the settlement period can impact incentives for flexible operations, we develop a simple example. We use the same incremental costs for the supplier as shown in the earlier example in Section 4.1. Figure 3 shows 12 5-minute LMPs from real LMP data. The solid lines are prices (left axis), which include actual LMPs ("5-Min Price") and the cumulative average LMP from the beginning of the hour to the current time period ("Moving Hrly Avg Price"). The dashed lines are different operating strategies: "5-Min Sched" the supplier follows a schedule, as in Section 4.1, based on the most efficient output level that the market operator computes and directs each 5-minute period; "Moving Hrly Avg Sched" the supplier follows an output that is based on the current hourly average LMP ("Moving Hrly Avg Price"); and "Perf Knowl Hrly Avg Sched" is the hypothetical example of what the most efficient output would be from the supplier if it had perfect knowledge of the final average hourly price. 


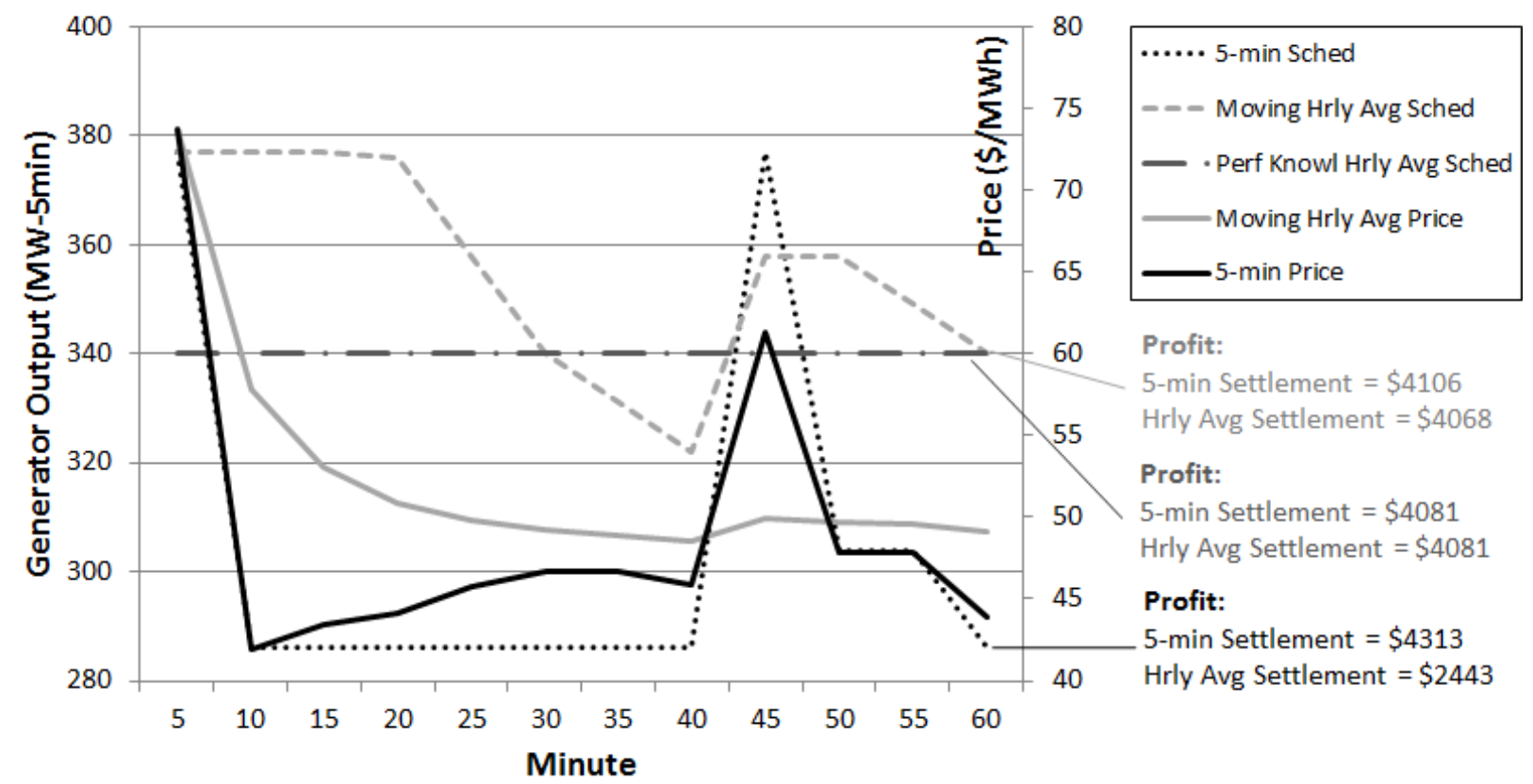

Figure 3. Profits of different scenarios with 5-minute settlements compared to average hourly settlements (adapted from Ela et al. 2014c)

Figure 3 shows how hourly average settlements may deter resources from providing 5-minute flexibility. An examination of the different dispatches (dashed lines) shows that the maximum flexibility is achieved with the market 5-minute scheduling scenario. The right column of Figure 3 also presents the total profit for each of the three scheduling scenarios with both 5-minute settlement and hourly average settlement procedures. With 5-minute settlements, following the market operator's 5-minute schedule is the most profitable $(\$ 4,313)$. In contrast, with settlements based on the hourly average as they are in many markets today, generating at a level that is different than the market operator's 5-minute schedule, and therefore inhibiting the flexibility that the market needs, is more profitable than following the market's 5-minute schedule (a profit of $\$ 2,443$ is substantially lower than the profit from the other two methods of chasing the hourly average). This shows that even though 5-minute scheduling is present in almost every U.S. energy market, it is important that the settlement interval length follow the same interval length as the scheduling to incentivize suppliers to provide the flexibility that is needed by the market operator. 


\subsection{Existing ancillary service markets}

A number of ancillary service markets exist in both day-ahead and real-time electricity markets. These services include active power capacity that is held as operating reserve and used for various reasons and at various timescales. These markets are usually co-optimized with the energy market so that the market operator is able to efficiently schedule suppliers for both energy and ancillary services and price both services accordingly. In co-optimized energy and ancillary service markets, the ancillary service prices will be set based on the bid-in cost to provide the ancillary service as well as the lost opportunity cost to provide energy or a separate ancillary service. This will cause suppliers indifference in providing energy or ancillary services and give further flexibility to the market operator.

Three ancillary services that are common among all U.S. markets are regulation, spinning, and non-spinning contingency reserves. All of these ancillary services limit the amount of capacity that can be sold to the market based on the response speed of the supplier. For example, regulating reserve typically limits the capacity by how much the resource can provide in 5 minutes. If two resources have $50 \mathrm{MW}$ of capacity available, with one having a 1-MW/minute ramp rate and another having a 2-MW/minute ramp rate, they would be able to provide $5 \mathrm{MW}$ and $10 \mathrm{MW}$ of regulating reserve, respectively. If the price of regulating reserve were $10 \$ / \mathrm{MW}$ $\mathrm{h}$, the second resource would receive $\$ 50$ more revenue than the first, even though they had the same capacity available. This is an obvious incentive for resources to improve flexibility by way of faster response rates.

\subsection{Make-whole payment guarantee}

Another way that suppliers can be incentivized to participate and offer their flexibility to the market is with make-whole payments, also called bid-production cost guarantees (e.g., NYISO), ${ }^{2}$ revenue sufficiency guarantees (e.g., Midcontinent ISO; MISO), ${ }^{3}$ and operating reserve credits (PJM). ${ }^{4}$ These retrospective payments ensure that suppliers that offer flexibility into the market are guaranteed not to lose money in the short term when participating and following the directions of the market operator. If the revenue that the supplier makes based on the market prices (LMP and ancillary service clearing price) is less than the supplier's bid cost, the supplier is made whole, with the market operator paying the supplier the difference as a side payment. 
Self-scheduled resources would not receive this guarantee, because they are not giving a bid-cost to the market nor are they offering the flexibility for the market operator to commit and dispatch the supplier's output.

\subsection{Day-ahead profit assurance}

Another settlement mechanism in place today to incentivize suppliers to participate and offer their flexibility to the market is the day-ahead margin assurance payment (DAMAP). This mechanism is in existence today in a number of ISOs. It ensures that when energy schedules are reduced in the real-time market from their day-ahead energy schedules, this will not adversely affect the profit margin the suppliers made in the day-ahead market. If the real-time market adjusted the supplier output such that it would receive more profit by not operating as the market operator suggests and operating as it was scheduled in the day-ahead market, reliability could be adversely affected. The DAMAP will incentivize resources to offer their flexibility in the realtime market by guaranteeing the profit it received from the day-ahead market regardless of realtime outcomes. The DAMAP applies to day-ahead energy and ancillary service markets. Selfscheduled resources that do not offer flexibility are not guaranteed this payment when output changes in real time. This results in a further incentive to offer flexibility to the market rather than self-scheduling.

\section{Emerging market design elements that impact flexibility incentives}

While all of the existing designs clearly incentivize flexibility and the offering of that flexibility to the system operator, it is unclear the extent to which they provide sufficient incentives to ensure an adequate level of system flexibility, particularly under increasing levels of VG penetration. Newer market mechanisms have also been proposed in many markets to incentivize flexibility in system operations. We discuss a number of more recent market design changes that may have some influence on incentivizing further flexibility from suppliers. 


\subsection{Flexibility from nontraditional resources}

Markets have started to allow for nontraditional resources, such as demand response, energy storage, and VG itself to provide flexibility, and they benefit from doing so. Given the characteristics of these emerging technologies, adjusting market rules to better align benefits and revenues that were designed with the traditional thermal and hydro technologies in mind may be required.

One of the most significant market rule changes has been made for the further adoption of demand-response resources as suppliers of energy and ancillary services. Federal Energy Regulatory Commission (FERC) Order 745 (FERC 2011a) directed the wholesale market operators to pay the energy LMP to demand-side resources that curtailed their load when directed, as long as a net-benefits test shows that providing the demand response reduced costs per unit to consumers. The increasing participation of demand response in wholesale markets is, however, subject to significant uncertainty due in large part to a recent U.S. Court of Appeals ruling that vacated FERC Order No. $745,{ }^{5}$ though CAISO has recently taken steps to incorporate more DR into its wholesale markets. ${ }^{6}$ In addition, many of the market operators have implemented ways in which demand can participate in ancillary service markets. For example, in the Electric Reliability Council of Texas (ERCOT), nearly half of the contingency reserve needed is supplied by demand-response resources that curtail when system frequency reaches some level below nominal frequency (Huang et al. 2009).

Energy storage is another resource that has tremendous flexibility with its large absolute power range, superior response rates, and much less limiting commitment constraints than thermal units. However, energy storage resources do have limitations on the amount of time they are able to sustain energy levels, ranging from minutes (e.g., flywheels) to days (e.g., large pumped storage hydro) and can be much more expensive that the provision of at least some demand-side resources. Some of the market operators have been adjusting market rules to allow for extraction of some of the tremendous flexibility from energy storage. For example, PJM now has full optimization of pumped storage resources in day-ahead markets (Ward 2011), and other markets have adjusted automatic generation control (AGC) algorithms to allow for extracting the extremely fast speed and flexibility of limited energy storage resources while keeping track of its energy discharge level (Allen et al. 2009). 
Recent changes have also enabled market operators to extract flexibility from VG. Previously, all VG was treated very similarly to negative load in that its output was considered to be fixed and other resources were required to adjust their outputs to account for the variability and uncertainty that occurred. However, due to transmission constraints or minimum generation constraints of thermal units, it was found that there are some instances in which VG could curtail its output quickly and help balance the system and maintain reliability and security limits at a lower cost than other flexibility options, even recognizing the opportunity cost of avoided energy sales. Several markets, including NYSIO, PJM, and MISO, have implemented some variation of this curtailment policy, thereby providing a great new source of flexibility.

In addition to VG providing flexibility in the energy market and assisting in transmission congestion management, recent discussions have also explored the ability of VG, particularly wind, to offer its flexibility in the ancillary service markets. Wind power can provide various forms of frequency control using a combination of mechanical pitch and torque control and power electronics control (Ela et al. 2014a). In many ways, it can provide a desired response faster than thermal plants. Multiple studies have looked at the ability of wind power to participate in regulating reserve markets (Kirby, Milligan, and Ela 2010; Liang, Grijalva, and Harley 2011; Tuohy et al. 2012) and have shown that, in certain instances, wind power can earn revenue and reduce total costs to consumers by providing regulating reserve. Other research has demonstrated that enabling VG to be a flexible resource can significantly improve market efficiency and increase the flexibility pool (Ela and Edelson 2012).

\subsection{Evolving regulating reserve markets (Order 755)}

Some recent changes have been made to the ancillary service markets to change the ways in which resources are incentivized. The most significant changes have been made to the regulating reserve markets with FERC Order 755 (FERC 2011b). The order directed wholesale market operators to include market-based payments for regulating reserve performance, lost opportunity costs for all regulating reserve capacity prices, and incentives and rules for accuracy. All U.S. markets have now implemented the changes for Order 755.

Historically, ancillary service markets are paid only for the capacity that suppliers held to provide the ancillary service and not the actual utilization of the capacity for the ancillary service 
(Rebours 2007). Additionally, in some markets, the lost opportunity cost was paid only to the suppliers that incurred these costs. With Order 755, payment for regulating reserves is adjusted for their actual performance, and the lost opportunity cost is part of the price paid to all regulating reserve suppliers. The performance price must be market-based rather than administratively set, and the performance is based on the absolute amount of movement that a supplier performs in a market interval. Suppliers that are asked to move up and down at a higher frequency would therefore be paid more for performance than those being asked to move more slowly. In addition, if a supplier follows the AGC signal more accurately, it would receive more revenue. This design would then incentivize resources that are more flexible and can provide regulating reserve faster and more accurately by providing greater payment than those made to slower and less accurate regulating reserve resources.

Order 755 better positions the regulating reserve market to incentivize response speed as well as response accuracy, giving a great push toward improved flexibility incentives. However, there was not a consensus on the benefits of the order. Opponents believed that the faster response would only raise costs to consumers while others suggested that the performance payment would reduce regulating reserve capacity prices and that the faster ramping resources would improve the efficiency of meeting regulating reserve requirements (e.g., Makarov et al. 2008). Table 2 shows ancillary service prices for a time period when Order 755 was implemented in NYISO (June 26, 2013) and then the prices for the same time period during the previous year without Order 755. Although this could have occurred for many reasons other than Order 755, prices for all ancillary services increased with the new design, not necessarily supporting the efficiency improvement argument. The impact of Order 755 on efficiency and reliability should continue to be evaluated.

Table 2. Ancillary Service Prices of the NYISO during a Period With and Without Regulation Performance Payments (Ela et al. 2014c)

\begin{tabular}{|c|c|c|c|c|c|}
\hline $\begin{array}{c}\text { Before } 755 \text { (June } \\
\text { 26- } \\
\text { Oct. 22, 2012) }\end{array}$ & $\begin{array}{l}\text { Spinning } \\
\text { (\$/MW-h) }\end{array}$ & $\begin{array}{c}\text { Nonspinning } \\
\text { (\$/MW-h) }\end{array}$ & $\begin{array}{l}\text { 30-min. } \\
\text { (\$/MW-h) }\end{array}$ & $\begin{array}{c}\text { Regulation } \\
\text { Capacity }\end{array}$ & $\begin{array}{c}\text { Regulation } \\
\text { Mileage (\$/MW) }\end{array}$ \\
\hline Average price & $\$ 4.00$ & $\$ 1.80$ & $\$ 0.08$ & $\$ 6.44$ & N/A \\
\hline $\begin{array}{l}\text { Average intervals at } 0 \\
\text { price }\end{array}$ & $84.5 \%$ & $98.0 \%$ & $99.9 \%$ & $0.4 \%$ & N/A \\
\hline
\end{tabular}




\begin{tabular}{|c|c|c|c|c|c|}
\hline $\begin{array}{c}\text { After } 755 \\
\text { (June 26-Oct. 22, } \\
\text { 2013) }\end{array}$ & $\begin{array}{l}\text { Spinning } \\
\text { (\$/MW-h) }\end{array}$ & $\begin{array}{c}\text { Nonspinning } \\
\text { (\$/MW-h) }\end{array}$ & $\begin{array}{l}\text { 30-min. } \\
\text { (\$/MW-h) }\end{array}$ & $\begin{array}{c}\text { Regulation } \\
\text { Capacity }\end{array}$ & $\begin{array}{c}\text { Regulation } \\
\text { Mileage }(\$ / M W)\end{array}$ \\
\hline Average price & $\$ 5.82$ & $\$ 3.26$ & $\$ 1.70$ & $\$ 10.59$ & $\$ 0.23(\$ 2.30)^{\mathrm{a}}$ \\
\hline $\begin{array}{l}\text { Average intervals at } 0 \\
\text { price }\end{array}$ & $86.4 \%$ & $98.1 \%$ & $99.4 \%$ & $1.4 \%$ & $10.2 \%$ \\
\hline
\end{tabular}

${ }^{a}$ NYISO uses a multiplier of 10 for regulation mileage, i.e., a typical unit will perform mileage equal to 10 times its capacity; therefore, multiplying the regulation mileage price by 10 can give a more relative comparison.

\subsection{Ancillary service markets for primary frequency control}

Another new ancillary service, primary frequency response, could also provide incentives to support reliability for resources that may not have had those incentives in the past. Primary frequency response (PFR) is the first stage of frequency control and typically is provided by synchronous generator turbine governors that respond automatically and proportionally to frequency deviations. A common criticism of Order 755 discussed in the previous section was that it considered only secondary frequency control, which follows the AGC signal, and not PFR, despite the strong interrelationship between the two. Essentially, the argument was that the faster a supplier can follow the AGC signal, the more it could earn, until the AGC signal is too fast and the supplier follows frequency, in which case the supplier gets paid nothing.

Frequency response is a growing issue for multiple reasons. First, frequency response in the United States, especially in the Eastern Interconnection, has been declining during the past 20 years or more (Ingleson and Allen 2010). Some reasons for this include high governor deadbands, generators operating in modes that do not offer frequency-responsive reserve, governors that are not enabled, and a reduced percentage of direct-drive motor load (Schulz 1999, Virmani 1999). Others claim that the wholesale electricity market design, lack of incentives, and even the presence of disincentives to provide the service are among the major causes of the decline (IEEE Task Force 2007). As an example of one potential disincentive, suppliers may be financially penalized for automatically providing PFR because such a frequency deviation exceeds the tolerance band around the scheduled output, as is standard practice per many markets' settlement rules (Ela et al. 2012). 
Secondly, without any controls or changes to meet the frequency needs, increased penetrations of nonsynchronous VG, which displace resources that typically offer PFR, could further degrade frequency response. To ensure sufficient PFR, NERC recently implemented the Frequency Response and Frequency Bias Setting standard BAL-003-1, which requires balancing authority areas to have a minimum amount of PFR. Other ancillary service market designs for PFR have been proposed in the literature (e.g., Ela et al. 2014b) and now also by ERCOT. Recently, in its ancillary service market redesign initiative, ERCOT was the first market to mention its intentions to implement a PFR ancillary service market (ERCOT 2013). After BAL-003-1 was passed, and with the increasing need to incentivize resources to be more flexible and provide these services, it is likely that other markets may follow suit..

\subsection{Pricing to reduce uplift}

Some differences occur in the way that each ISO prices energy and ancillary services. For energy markets, pricing in some regions is not based on the pure marginal cost. MISO has discussed the Extended LMP (ELMP), which is based on the convex-hull pricing concept (Gribik et al. 2011, Gribik et al. 2007) and is similar to the hybrid-dual approach at NYISO (FERC 2001). The ELMP and hybrid-dual pricing concepts consider the non-convex aspects of the resource costs and constraints part of their pricing rules. Certain resources will include the no-load and/or startup cost of the resource as part of its total bid cost, meaning that these non-convex costs are incorporated as convex costs and can influence the price, which is traditionally based solely on incremental energy costs. While these resources provide the same schedule, the prices are calculated in ways where the scheduling problem is "convexified." The design will also relax minimum capacity limits for pricing purposes, such that more resources are able to set the price. The benefit of this approach is more transparency in pricing to the more expensive resources by having prices better reflect actual costs, including non-convex cost elements. The need for makewhole payments is therefore also reduced under these pricing schemes. The convex-hull and similar pricing approaches are currently an ongoing debate and an important market design research topic. 


\subsection{Flexible ramping products}

Finally, explicit ancillary service products for flexible ramping provision, as has been proposed in the California Independent System Operator (CAISO), may be able to provide specific incentives that make resources more inclined to provide greater flexibility when the flexibility is needed in system operations. Previous studies conducted by CAISO revealed greater flexibility needs with growing levels of VG in its system: ramping needs and load-following capacity requirements would increase and certain load-following requirements would be unmet in some hours unless some self-scheduled resources changed to become flexible resources (CAISO 2007, CAISO 2010a). In response, CAISO introduced its flexible ramping constraint mechanism in 2011 (CAISO 2011, Abdul-Rahman et al. 2012), commonly referred to as "FlexiRamp." This is an additional constraint added to the market-clearing engine that ensures that sufficient upward ramping capacity is committed and available in the real-time commitment and real-time dispatch process. The use of this flexibility constraint reduces infeasibilities in the dispatch procedure compared to when ramp capability is not committed, reduces the need to rely on regulating reserve and on neighboring balancing errors, and eliminates the need to biased hour-ahead forecasts to prepare for potential variations in real time. The amount of ramp capability that is required in the constraint is determined by the CAISO operators based on the (1) expected level of variability for the interval, (2) potential uncertainty as a result of load and VG forecast errors, and (3) differences between the hourly, 15-minute average net load levels and the actual 5minute net load levels. Units that incur a lost opportunity cost by withholding their capacity from other ancillary services to meet this ramping constraint are compensated at an amount equal to the system's incremental cost of increasing the ramping need by one unit.

CAISO is now proposing to extend this market product to include downward ramping, use the 5minute real-time dispatch interval rather than the 15-minute real-time pre-dispatch model, include the product in the day-ahead market, and implement a flexibility demand curve to account for both variability (known ramps) and uncertainty (unforeseen ramps). Because CAISO uses a multi-period market-clearing engine, ramping requirements are already within the model based on the expected change in net load from one interval to the next. This is the minimum ramping requirement that must be met. The ISO then will require additional ramping capability requirements above the expected ramping requirement to meet unexpected ramping needs. 
The importance of the flexible ramping product can be illustrated with some short examples from $\mathrm{Zu}$ and Tretheway (2012). The first example (Table 4) is a two-period dispatch solution with 5minute intervals, with a load of $420 \mathrm{MW}$ in Interval 1 and $590 \mathrm{MW}$ in Interval 2. The second example (Table 5) is the same scenario with a flexible ramping product requirement set to require slightly more ramping capability than the inherent need from the first scenario (170.01 MW in 5 minutes). Both scenarios use a two-generator set with characteristics shown in Table 3. Both generators have zero-cost bids for flexible ramping and minimum generation levels at 0 MW.

Table 3. Generator Properties for Flexible Ramp Example (data extracted from Zu and Tretheway 2012)

\begin{tabular}{l|l|l|l}
\hline Generator & $\begin{array}{l}\text { Bid Cost } \\
\mathbf{( \$ / M W h )}\end{array}$ & $\begin{array}{l}\text { Ramp Rate } \\
\text { (MW/min) }\end{array}$ & Pmax \\
\hline Gen 1 & 25 & 100 & 500 \\
Gen 2 & 30 & 10 & 500 \\
\hline
\end{tabular}

Table 4. Scenario 1, Multi-Interval Dispatch (data extracted from Zu and Tretheway 2012)

\begin{tabular}{l|l|l|l|l}
\hline \multirow{2}{*}{ Generator } & \multicolumn{2}{|c|}{$\begin{array}{c}\text { Interval 1 } \\
\text { (LMP=25\$/MWh) }\end{array}$} & \multicolumn{2}{c}{$\begin{array}{c}\text { Interval 2 } \\
\text { (LMP=35\$/MWh) }\end{array}$} \\
\cline { 2 - 5 } & Energy & Flex & Energy & Flex \\
\hline G1 & 380 & 0 & 500 & 0 \\
\hline G2 & 40 & 0 & 90 & 0 \\
\hline
\end{tabular}

Table 5. Scenario 2, Flexibility Reserve Product (data extracted from Zu and Tretheway 2012)

\begin{tabular}{l|l|l|l|l}
\hline \multirow{2}{*}{ Generator } & \multicolumn{2}{|c|}{$\begin{array}{c}\text { Interval 1 } \\
\text { (LMP=\$30/MWh, } \\
\text { FRP=5\$/MWh) }\end{array}$} & \multicolumn{2}{c}{$\begin{array}{c}\text { Interval 2 } \\
(\text { LMP=30\$MWh) }\end{array}$} \\
\cline { 2 - 5 } & Energy & Flex & Energy & Flex \\
\hline G1 & 379.99 & 120.01 & 500 & 0 \\
G2 & 40.01 & 50 & 90 & 0 \\
\hline
\end{tabular}


Both scenarios have essentially identical operational results; however, the prices that result are quite different in each scenario because of the flexible ramping requirement. The first scenario would not have the same incentive for providing flexibility as would the second scenario. This example shows some benefit of the flexible ramp product when expected variability is present. The product will also increase the ramping need above the expected ramp to be able to meet the unexpected ramp need (ramp needs that are not forecasted). This allows for resources to have capacity and ramp available in case a ramping event occurs. Pricing based on the lost opportunity cost allows all resources to be indifferent whether providing flexible ramping or energy either for certain or uncertain ramping events.

MISO has proposed a similar product to CAISO with its up-ramp capability and down-ramp capability product (Navid and Rosenwald 2012, Navid et al. 2011). MISO had claimed that the most common reason for scarcity pricing conditions in its area was not caused by limited capacity but by insufficient ramp capability. The product has similar concepts to CAISO, including a demand curve for insufficient ramp capability, pricing based solely on the lost opportunity costs from other products, and a requirement based on historical information to meet both expected and unexpected ramping requirements. The product has been filed with FERC and is expected to be introduced into the market in 2016 (MISO 2015).

\section{Conclusion}

The existing U.S. wholesale electricity markets aim to incentivize the investment in and operation of resources to provide a variety of services, including energy and various ancillary services. However, it is unclear whether current market designs are incentivizing resources that have flexible capabilities to offer those capabilities to the short-term energy and/or ancillary services market when active power flexibility is needed the most. We discussed the importance of short-term flexibility in system operations, how that flexibility is needed to better accommodate the increased variability and uncertainty of VG, how markets have traditionally met flexibility needs, and how markets are evolving to incentivize flexibility. We also showed that flexibility means many things, whether it is the speed of power adjustments, the range of power that can be provided, or just the fact that it can autonomously respond to a frequency deviation. 
Market designers have established numerous traditional mechanisms to incentivize resources to offer their flexibility to the market as well as newer mechanisms that attempt to further incentivize increasing levels of flexibility when that flexibility is needed, particularly as a result of growing penetrations of VG. Most of the flexibility needs can be met by existing market processes, tools, and methods, such as centralized scheduling and efficient dispatch, frequent scheduling and settlement intervals, and make-whole payments. However, sometimes new scheduling strategies or improved methods may more efficiently extract the flexibility that is needed from the system resources. For example, new ancillary service market designs, such as pay-for-performance regulation and primary frequency response markets, provide additional incentives to support reliability for resources that may not have had those incentives in the past. Additionally, explicit products for flexible ramping provision, as has been proposed in CAISO and MISO, may be able to provide specific incentives that make resources more inclined to provide greater flexibility when the flexibility is needed in system operations, as might result from increasing VG. Other new market mechanisms to provide flexibility include the allowance for nontraditional resources, such as demand response, energy storage, and even VG itself.

Moving forward, however, the various regional markets have not yet converged on approaches to incentivize active power flexibility in short-term markets. One size does not necessarily fit all when it comes to electricity market designs, and each area has solved its historical issues through specific designs involving the stakeholders and market participants in each area. For example, some regions have decided that a flexible ramping provision like that proposed by CAISO and MISO is unnecessary and that current mechanisms may already be sufficient to incentivize further flexibility. Whether these differences are because of regional differences in the system characteristics, generating portfolios (e.g., amount of self-scheduled bilateral agreements and generator fleet composition), or existing market rules or procedures is still undetermined. The topic of flexibility incentives should take a more holistic view to see what the reasons are for further market design changes, how these changes should occur, and how increasing amounts of variable energy resources may affect the need for market design changes. 


\section{Acknowledgements}

The National Renewable Energy Laboratory's contribution to this work was supported by the U.S. Department of Energy under Contract No. DE-AC36-08GO28308 with the National Renewable Energy Laboratory. Argonne National Laboratory's contribution was supported by the U.S. Department of Energy under Contract No. DE AC02-06CH11357 with Argonne National Laboratory. Funding provided by U.S. DOE Office of Energy Efficiency and Renewable Energy. The U.S. Government retains and the publisher, by accepting the article for publication, acknowledges that the U.S. Government retains a nonexclusive, paid up, irrevocable, worldwide license to publish or reproduce the published form of this work, or allow others to do so, for U.S. Government purposes.

\section{References}

Abdul-Rahman, K., Alarian, H., Rothleder, M., Ristanovic, P., Vesovic, B., Lu, B., 2012. Enhanced system reliability using flexible ramp constraint in CAISO market. IEEE Power and Energy Society General Meeting Proceedings; July 22-26, 2012, San Diego.

Allen, A., Brown, C., Hickey, J., Le, V., Safuto, R., 2009. Energy Storage in the New York Electricity Market. Draft white paper. New York Independent System Operator, Rensselaer, NY. http://www.nyiso.com/public/webdocs/markets operations/committees/bic miwg/meeting materials /2010-01-21/Energy_Storage_Resources.pdf.

Bertsimas, D., Litvinov, E., Sun, X., Zhao, J., Zheng, T., 2013. Adaptive robust optimization for the security constrained unit commitment problem. IEEE Transactions on Power Systems 28(1) Feb.: pp. $52-63$.

Bouffard, F., Galiana, F., 2008. Stochastic security for operations planning with significant wind power generation. IEEE Transactions on Power Systems 23(2) May: pp. 306-316.

CAISO, 2007. Integration of Renewable Resources: Transmission and Operating Issues and Recommendations for Integrating Renewable Resources on the California ISO-Controlled Grid. Folsom, CA. http://www.caiso.com/1ca5/1ca5a7a026270.pdf.

CAISO, 2010a. Integration of Renewable Resources: Operational Requirements and generation Fleet Capability at 20\% RPS. Folsom, CA. http://www.caiso.com/2804/2804d036401f0.pdf.

CAISO, 2010b. Market Issues and Performance Annual Report. Folsom, CA. http://www.caiso.com/2b66/2b66baa562860.pdf.

CAISO, 2011. Opportunity Cost of Flexible Ramping Constraint: Draft Final Proposal. Folsom, CA. http://www.caiso.com/Documents/DraftFinalProposal-FlexibleRampingConstraint.pdf.

Public Utility Commission of the State of California (CPUC), 2014. Decision Resolving Several Phase Two Issues and Addressing the Motion for Adoption of Settlement Agreement on Phase Three Issues. http://docs.cpuc.ca.gov/PublishedDocs/Published/G000/M143/K552/143552239.pdf 
Ela, E., Edelson, D., 2012. Participation of wind power in LMP-based energy markets. IEEE Transactions on Sustainable Energy 3(4) Oct.

Ela, E., Gevorgian, V., Fleming, P., Zhang, Y.C., Singh, M., Muljadi, E., Scholbrook, A., Aho, A., Buckspan, A., Pao, L., Singhvi, V., Tuohy, A., Pourbeik, P., Brooks, D., Bhatt, N., 2014a. Active Power Control from Wind Power: Bridging the Gaps. NREL/TP-5D00-60574. National Renewable Energy Laboratory, Golden, CO. http://www.nrel.gov/docs/fy14osti/60574.pdf.

Ela, E., Gevorgian, V., Tuohy, A., Kirby, B., Milligan, M., O’Malley, M., 2014ab. Market designs for the primary frequency response ancillary service-Part I: Motivation and design. IEEE Transactions on Power Systems 29(1) Jan.

Ela, E., Milligan, M., Bloom, A., Botterud, A., Townsend, A., Levin, T., 2014c. Evolution of Wholesale Electricity Market Design with Increasing Levels of Renewable Generation. NREL/TP5D00-61765. National Renewable Energy Laboratory, Golden, CO.

http://www.nrel.gov/docs/fy14osti/61765.pdf.

Ela, E., O’Malley, M., 2012. Studying the variability and uncertainty impacts of variable generation at multiple timescales. IEEE Transactions on Power Systems 27(3). http://ieeexplore.ieee.org/xpl/articleDetails.jsp?arnumber=6166377.

Ela, E., Tuohy, A., Milligan, M., Kirby, B., Brooks, D., 2012. Alternative approaches for incentivizing the PFR ancillary service. The Electricity Journal 25(4) May: pp. 88-102.

ERCOT, 2013. Future ancillary services in ERCOT. ERCOT concept paper, Draft version 1.0. Austin, TX.

http://www.ercot.com/content/news/presentations/2014/ERCOT\%20AS\%20Concept\%20Paper\%20V ersion\%201_0\%20as\%20of\%209-27-13\%201745.pdf.

FERC, 2001. Order on Motion to Implement Hybrid Fixed Block Pricing Rule and Requiring Tariff Filing, Acting on Related Requests for Rehearing, and Accepting Preliminary Report, 95 FERC II 61,121, FERC Stats \& Regs., April 26.

FERC, 2011a. Demand Response Compensation in Organized Wholesale Energy Markets, 134 FERC II 61,187, Order No. 745, FERC Stats. \& Regs., March 15. http://www.ferc.gov/EventCalendar/Files/20110315105757-RM10-17-000.pdf.

FERC, 2011b. Frequency Regulation Compensation in the Organized Wholesale Power Markets, 138 FERC II 61,123, Order No. 755, FERC Stats. \& Regs., October 20. http://www.ferc.gov/whatsnew/comm-meet/2012/021612/E-3.pdf.

FERC, 2014. Staff Analysis of Operator- Initiated Commitments in RTO and ISO Markets. Price Formation in Organized Wholesale Electricity Markets, Docket No. AD14-14-000, December. http://www.ferc.gov/legal/staff-reports/2014/AD14-14-operator-actions.pdf

Gribik, P.R., Chaterjee, D., Navid, N., Zhang, L., 2011. Dealing with uncertainty in dispatching and pricing in power markets. IEEE Power and Energy Society General Meeting Proceedings; July. 
Gribik, P.R., Hogan, W.W., Pope, S.L., 2007. Market-clearing electricity prices and energy uplift. Accessed May 2014:

https://www.misoenergy.org/Library/Repository/Meeting\%20Material/Stakeholder/Workshops\%20a nd\%20Special\%20Meetings/2010/Convex\%20Hull\%20Pricing\%20Workshops/20091030\%20Marke t-Clearing\%20Electricity\%20Prices\%20and\%20Energy\%20Uplift.pdf

Huang, S., Dumas, J., Gonzalez-Perez, C., Wei-Jen, L., 2009. Grid Security Through Load Reduction in the ERCOT Market. IEEE Transactions on Industry Applications 45(2) March-April.

IEEE Task Force, 2007. IEEE Task Force on large interconnected power systems response to generation governing: Present practice and outstanding concerns. IEEE Special Publication 07TP180.

Ingleson, J., Allen, E., 2010. Tracking the Eastern Interconnection frequency governing characteristic. IEEE Power and Energy Society General Meeting Proceedings; July, Minneapolis.

Kirby, B., Milligan, M., Ela, E., 2010. Providing minute-to-minute regulation from wind power plants. 9th Annual International Workshop on Large-Scale Integration of Wind Power into Power Systems and Transmission Networks for Offshore Wind Power Plants Conference Proceedings; Oct., Quebec, Canada.

Liang, J., Grijalva, S., Harley, R., 2011. Increased wind revenue and system security by trading wind power in energy and regulation reserve markets. IEEE Transactions on Sustainable Energy 2(3), July: pp. 340-347.

Makarov, Y., Lu, S., Ma, J., Nguyen, T.B., 2008. Assessing the Value of Regulation Resources Based on Their Time Response Characteristics. PNNL-17632. California Energy Commission, Public Interest Energy Research Program, Sacramento, CA.

Meibom, P., Barth, R., Larsen, H., Brand, H., Tuohy, A., Ela, E., 2011. Advanced Unit Commitment Strategies in the United States Eastern Interconnection. NREL/SR-5500-49988. National Renewable Energy Laboratory, Golden, CO. http://www.nrel.gov/docs/fy11osti/49988.pdf.

Midcontinent Independent System Operator (MISO), 2015. Amended Supplemental Filing of the Midcontinent Independent System Operator, Inc. to Ramp Capability Product Filing; FERC Docket No. ER14-2156-001. https://www.misoenergy.org/Library/Repository/Tariff/FERC\%20Filings/201504-16\%20Docket\%20No.\%20ER14-2156-001.pdf

Milligan, M., Frew, B., Bloom, A., Ela, E., Botterud, A., Townsend, A., Levin, T., 2016. Wholesale electricity market design with increasing levels of renewable generation: Part 1-Revenue sufficiency and long-term reliability. Electricity Journal, March.

Milligan, M., Kirby, B., 2010. Market Characteristics for Efficient Integration of Variable Generation in the Western Interconnection. NREL/TP-550-48192. National Renewable Energy Laboratory, Golden, CO. http://www.nrel.gov/docs/fy10osti/48192.pdf.

Milligan, M., Kirby, B., Beuning, S., 2010. Combining balancing areas' variability: impacts on wind integration in the Western Interconnection. NRELICP-550-48249. National Renewable Energy Laboratory, Golden, CO. 
Monitoring Analytics, LLC, 2010. State of the Market Report for PJM: Section II-Energy Market, Part I. Eagleville, PA.

http://www.monitoringanalytics.com/reports/PJM_State_of_the_Market/2010/2010-som-pjmvolume2-sec2.pdf.

Navid, N., Rosenwald, G., 2012. Market solutions for managing ramp flexibility with high penetration of renewable resource. IEEE Transactions on Sustainable Energy 3(4): pp.784-790.

Navid, N., Rosenwald, G., Chatterjee, D., 2011. Ramp Capability for Load Following in the MISO Markets. MISO Market Development and Analysis, Carmel, IN.

https://www.midwestiso.org/Library/Repository/Communication\%20Material/Key\%20Presentations \%20and\%20Whitepapers/Ramp\%20Capability\%20for\%20Load\%20Following\%20in\%20MISO\%20 Markets\%20White\%20Paper.pdf.

Price, J.E., Rothleder, M., 2011. Recognition of extended dispatch horizons in CA energy markets. IEEE Power and Energy Society General Meeting Proceedings; July 24-29, Detroit.

Rebours, Y., Kirschen, D., Trotignon, M., 2007. Fundamental design issues in markets for ancillary services. The Electricity Journal 20(11): pp. 26-34.

Schulz, R., 1999. Modeling of governing response in the Eastern Interconnection. IEEE Power Engineering Society Winter Meeting Proceedings; Feb., New York.

Tuohy, A., Ela, E., Kirby, B., Brooks, D., 2012. Provision of regulation reserve from wind power: Economic benefits and steady-state system operation implications. 11th International Workshop on Large-Scale Integration of Wind Power into Power Systems and Transmission Networks for Offshore Wind Power Plants Conference Proceedings; Lisbon.

Virmani, S., 1999. Security impacts of changes in governor response. IEEE Power Engineering Society Winter Meeting Proceedings; Feb., New York.

Ward, M., 2011. Resource Commitment and Dispatch in the PJM Wholesale Electricity Market. http://www.ferc.gov/CalendarFiles/20110628072854-Jun28-SesA2-Ward-PJM.pdf

Zhou Z., Botterud A., 2014. Dynamic Scheduling of Operating Reserves in Co-optimized Electricity Markets with Wind Power. IEEE Transactions on Power Systems, Vol. 29, No. 1, pp.160-171.

Zu, L., Tretheway, D., 2012. Flexible Ramping Performance: Second Revised Draft Final Proposal. CAISO, Folsom, CA. http://www.caiso.com/Documents/SecondRevisedDraftFinalProposalFlexibleRampingProduct.pdf

\footnotetext{
${ }^{1}$ This is a simplistic example; for a more rigorous analysis of this topic, these constraints should be included.

${ }^{2}$ NYISO Market Services Tariff, accessed May 2014.

${ }^{3}$ MISO Business Practices Manual-005, Market Settlements, accessed May 2014.

${ }^{4}$ PJM Manual 28: Operating Agreement Accounting, Revision: 65, Effective Date 4/24/2014, accessed May 2014.

${ }^{5}$ See http://www.cadc.uscourts.gov/internet/opinions.nsf/DE531DBFA7DE1ABE85257CE1004F4C53/\$file/111486-1494281.pdf.

${ }^{6}$ CAISO's three IOUs implemented the first (pilot) phase of its Demand Response Auction Mechanism (DRAM) in October 2015, which sets a minimum amount of capacity that must be offered from among a wide range of DR resources in a pay-as-bid auction of monthly system resource adequacy (CPUC 2014).
} 